\title{
Renal Pelvis Urothelial Papilloma
}

National Cancer Institute

\section{Source}

National Cancer Institute. Renal Pelvis Urothelial Papilloma. NCI Thesaurus. Code C4528.

A benign neoplasm of the renal pelvis that involves the transitional epithelium projecting above the surrounding epithelial surface and consisting of villous or arborescent outgrowths of fibrovascular stroma. 